\title{
Association of Level of Physical Exertion with Acute Myocardial Infarction in Bangladeshi Population
}

\author{
Md. Kamrul Azad ${ }^{1}$, Abdul Wadud Chowdhury², Mohammad Arifur Rahman ${ }^{3}$, Shohael M Arafat ${ }^{4}$, \\ Sheikh Foyez Ahmed ${ }^{4}$, Sathi Dastider ${ }^{5}$ \\ 1250 Bedded TB Hospital, Shamoli, Dhaka, ${ }^{2}$ Department of Cardiology, Dhaka Medical College, \\ ${ }^{3}$ Department of Cardiology, NICVD, Dhaka, ${ }^{4}$ Department of Cadiology, Bangabandhu Sheikh Mujib \\ Medical University, Dhaka, ${ }^{5}$ Department of Maternal and Child Health, NIPSOM, Dhaka
}

Key Words:

Physical

Exertion, Acute

Myocardial

Infarction.

\begin{abstract}
Background: Evidences suggest that heavy physical exertion can trigger the onset of acute myocardial infarction. But there have been no clean cut data in Bangladesh about the risk of myocardial infarction during and after heavy exertion. To address this question the study was conducted.

Methods: It was a multicentre cross sectional study was conducted from July 2012 to June 2013 with patient of diagnosed acute myocardial infarction (AMI) admitted in department of cardiology of National Institute of Cardiovascular Diseases (NICVD), Bangabandhu Sheikh Mujib Medical University (BSMMU) and Dhaka Medical College Hospital (DMCH). From selected samples, two hours activity prior to onset of symptom of AMI was asked according to standard questionnaire. Activities were quantified on a scale from 1 to 8 metabolic equivalents (METs) according to generally accepted values. Collected data were analyzed by SPSS version 16.

Results: In this study 246 patients (74.4 percent of whom were men; mean age [ $\pm S D], 64.68 \pm 7.63$ years) were interviewed. The study showed that $11.38 \%$ patients were engaged in strenuous physical exertion (e" 6 METs) within two hours prior to symptom onset of AMI. Strenuous exertion group of AMI patients were all most all sedentary worker [26 (92.86\%) of 28]. Most of the patients (82.14\%) of strenuous group had history of less than 8 hours work per day. Strenuous exertion group had history of longtime exertion (72.57\%, 1-2 hours) than non-strenuous group $(42.66 \%,<0.5$ hours). Moreover, $67.86 \%$ AMI patients of strenuous exertion group had experienced irregular exertion whereas most of the patients (64.22\%) of non strenuous group had a history of regular exertion.

Conclusions: The result of the study indicates that a period of strenuous physical activity is associated with increased risk of having AMI, particularly among patients of sedentary worker who have dyslipidemia and who exercise irregularly. Those who exercise regularly have lower chances of $A M I$ as shown by the negative correlation.
\end{abstract}

(Cardiovasc. j. 2016; 8(2): 115-122)

\section{Introduction:}

An individual's long-term risk of AMI is determined, at least in part, by 'traditional' chronic risk factors, such as lipid levels, long-term average blood pressure, smoking habits and novel risk factors associated with increased vascular inflammation, such as C-reactive protein. ${ }^{1}$ However, based on an individual's risk, acute events may be precipitated or triggered by discrete transient exposures including physical, psychological, or chemical stresses. ${ }^{2}$

Quantitatively, the period of intense exercise and subsequent recovery is associated with about a 6 fold higher myocardial infarction rate. One observed mechanism for this phenomenon is the increased arterial pulse pressure stretching and relaxing of arteries with each heart beat which, as has been observed by intravascular ultrasound, increases mechanical "shear stress" on atheromas and the likelihood of plaque rupture and ultimately occlusion by thrombus at area of coronary artery.

Clarification of the role of physical exertion in triggering myocardial infarction is important for several reasons. It is estimated that more than 1.5 million myocardial infarctions occur annually in the United States, and at least 75,000 of these infarcts which lead to 25,000 deaths may occur soon after exertion. ${ }^{2,4}$ However the American Heart Association has recently recommended increased physical activity as an important way to reduce the risk of heart attack. ${ }^{5}$ Heavy physical exertion therefore appears to be a two-edged sword, both triggering and preventing myocardial infarction.

Address of correspondence: Dr. Mohammad Arifur Rahman, Department of Cardiology, National Institute of Cardiovascular Diseases, Dhaka, Bangladesh. E-mail: drarif79@yahoo.com 
Despite evidences ${ }^{6}$ suggesting that heavy physical exertion can trigger the onset of acute myocardial infarction in different countries but there have been no clean cut data in Bangladesh of the risk of myocardial infarction during and after heavy exertion, the length of time between heavy exertion and the onset of symptoms (induction time), and whether the risk can be modified by regular physical exertion. To address these questions, the study was done.

\section{Methods:}

This multicentre cross sectional study was conducted in Department of Cardiology of National Institute of Cardiovascular Diseases (NICVD), Bangabandhu Sheikh Mujib Medical University (BSMMU) and Dhaka Medical College Hospital (DMCH) from July 2012 to June 2013 in order to get relative risk of acute myocardial infarction within 2 hours of physical exertion. Sample were selected from the population by non-probability sampling technique and were excluded those who were disagree to participate in the study and those who had severe co-morbidity. From selected samples, two hours activity prior to onset of symptom of AMI was asked according to standard questionnaire. Activity was quantified on a scale from 1 to 8 metabolic equivalents (METs) according to generally accepted values.

\section{Level of physical exertion:}

The degree of physical exertion is quantified on a scale from 1 to 8 metabolic equivalents (MET) according to generally accepted values. ${ }^{7}$

1 MET is defined as the energy expended per minute by a subject sitting quietly and is equivalent to3.5 ml of oxygen per kilogram of body weight per minute by a $70-\mathrm{kg}$ adult. ${ }^{7,8}$

\begin{tabular}{|c|c|c|}
\hline $\begin{array}{l}\text { Estimated No. } \\
\text { of MET }\end{array}$ & Description & Type of Activity \\
\hline 1 & Sleeping, reclining & Sunbathing, lying on a couch watching television \\
\hline 2 & Sitting & $\begin{array}{l}\text { Eating, reading, desk work, sitting watching tele- } \\
\text { vision, driving on the highway }\end{array}$ \\
\hline 3 & Very light exertion & $\begin{array}{l}\text { Office work, driving in the city, personal care. } \\
\text { standing in line, strolling in a park }\end{array}$ \\
\hline 4 & $\begin{array}{l}\text { Light exertion, with normal } \\
\text { breathing }\end{array}$ & $\begin{array}{l}\text { Mapping, slow walking (e.g., shopping), bowling, } \\
\text { sweeping, golfing with a cart, gardening with } \\
\text { power tools }\end{array}$ \\
\hline 5 & $\begin{array}{l}\text { Moderate exertion, with deep } \\
\text { breathing }\end{array}$ & $\begin{array}{l}\text { Normal walking, golfing on foot, slow biking, } \\
\text { downhill skiing, calisthenics, raking leaves, } \\
\text { cleaning windows, hanging wallpaper, inte- } \\
\text { rior painting, hunting, fishing, slow dancing, } \\
\text { light restaurant work (e.g., waiting tables, } \\
\text { serving drinks) }\end{array}$ \\
\hline 6 & $\begin{array}{l}\text { Vigorous exertion, with panting; } \\
\text { overheating }\end{array}$ & $\begin{array}{l}\text { Slow jogging, speed-walking, tennis, swimming, } \\
\text { cross-country skiing, shoveling snow, fast bik- } \\
\text { ing, mowing with a push mower, pruning trees } \\
\text { or shrubs, heavy gardening, factory assembly } \\
\text { work, heavy household repairs, climbing up and } \\
\text { down a ladder, overhead work, ice hockey, } \\
\text { drills, softball, picking up garbage, laying } \\
\text { bricks, hurried heavy restaurant work }\end{array}$ \\
\hline 7 & $\begin{array}{l}\text { Heavy exertion, with gasping: } \\
\text { much sweating }\end{array}$ & $\begin{array}{l}\text { Running, fast jogging, nonstop racquetball, push- } \\
\text { ing a car stuck in snow, moving boulders, } \\
\text { changing tires, shoveling heavy or deep snow, } \\
\text { mixing cement, competitive basketball, touch } \\
\text { football, hanging drywall, putting down wall- } \\
\text { to-wall carpet, ladder or stair climbing with } \\
\text { a } 23 \text {-kg load, using a jackhammer }\end{array}$ \\
\hline 8 & Extreme or peak exertion & $\begin{array}{l}\text { Sprinting, fast running, jogging uphill, aggressive sports } \\
\text { with frequent sprinting and no rest, pushing or } \\
\text { pulling with all one's might, unusually extreme work }\end{array}$ \\
\hline
\end{tabular}




\section{Data collection procedure}

Information was collected from the patients according to a standardized interview after their transfer from the coronary care unit to PCCU or general ward. The interview covered demographic variables, medical history, cardiac risk factors, the timing and characteristics of symptoms, physical activity, unusual life events, circumstances of the myocardial infarction, sleeping and waking habits, activities, and any factors suspected by the patients of triggering myocardial infarction.

\section{Data analysis:}

Data obtained from the interview were analyzed and significance of differences was estimated by using statistical methods. Variables were analyzed by chi-square test, t-test where applicable. Correlations done by Pearson's correlation t-test where applicable. $\mathrm{P}$ value $\mathrm{P}<0.05$ were considered as significant. Statistical analyses were performed with SPSS, version 16.0 (SPSS Inc).

\section{Results:}

A total of 246 patients were enrolled in the study and among them $28(11.38 \%)$ patients had the history of heavy exertion [e^ 6 MET] (table-I). Analysis shows that gradually number of patients was increased with the exertion level MET-8 to MET - 1 and correlation is highly negative (Figure1). The activities reported by the patients included heavy house-hold work $(n=2)$, exaggerated physical activity at work $(\mathrm{n}=6)$, walking up flights of stairs $(n=2)$, speed walking $(n=2)$, over head work $(n=1)$, running $(\mathrm{n}=2)$, fast jogging $(\mathrm{n}=2)$, mixing cement $(n=1)$, van pulling $(n=2)$, rickshaw pulling $(n=1)$ climbing up and down a ladder with load $(n=2)$ unusually hard work $(\mathrm{n}=4)$ and playing football $(n=1)$.

Demographic characteristics of the sample showed that $74.4 \%$ were male and $25.6 \%$ were female. Male were more in strenuous group than non-strenuous group $(92.86 \%$ male in 28 strenuous exertion grouped patient) which was shown in table-I. Mean age of the patients was 64.68 years whereas mean age of strenuous group was 60.67 years and mean age of non-strenuous group was 65.03 years. So it is clear that

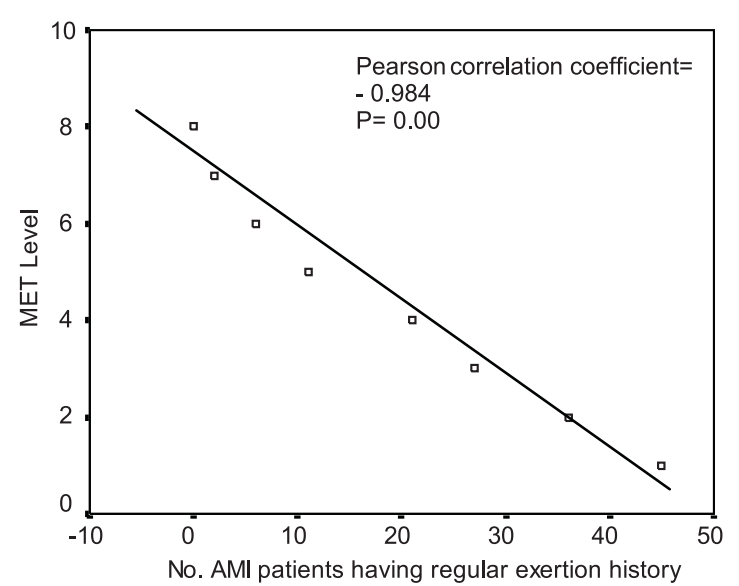

Fig.-1. Correlation of $A M I$ and regular physical Exertion at different MET level $(n=246)$.

strenuous exertion doing patients were younger than non-strenuous group (Table-I).

All risk factor were more in strenuous group patients than non-strenuous group except dyslipidemia. In non-strenuous group, $67.43 \%$ were smoker, $77.98 \%$ had the history of angina, $50.46 \%$ were diabetic, $76.61 \%$ were hypertensive and only $22.48 \%$ were dyslipidemic. On the other hand, in strenuous group $10.71 \%$ were smoker, $46.43 \%$ had the history of angina, $14.29 \%$ were diabetic, $32.14 \%$ were hypertensive and $67.86 \%$ were dyslipidemic (Table II).

In professional category in strenuous group, most of the patients were sedentary worker (26 patients out of 28 patients) whereas in strenuous group, most patients were physical worker (69.27\%). Strenuous group patients worked very few hours of the day ( $<8$ hours/day) in comparison to non strenuous group, most of them (68.81\%) worked 8-16 hours per day. In strenuous group, $82.14 \%$ $(46.43 \%+35.71 \%)$ patient had the history of AMI within 1 hour of symptom onset. But more than half of non-strenuous group patient had history of AMI after 1 hour of symptom onset (Table-III). In strenuous group, $78.57 \%$ had more than 1 hour exertion history and $78.57 \%$ had irregular exertion history. Whereas, in non-strenuous group, only $36.70 \%$ had long duration exertion history and $20.18 \%$ had done irregular exertion (Table IV). 
Table-I

Incidence of AMI at different level of physical exertion with sex and age distribution $(n=246)$.

\begin{tabular}{|c|c|c|c|c|c|c|}
\hline \multirow{2}{*}{\multicolumn{2}{|c|}{ Level of Exertion }} & \multirow{3}{*}{$\begin{array}{c}\text { Frequency } \\
\text { N (\%) } \\
50(20.3)\end{array}$} & \multicolumn{2}{|c|}{ Sex } & \multicolumn{2}{|c|}{ Age } \\
\hline & & & \multirow{2}{*}{$\begin{array}{c}\text { Male } \\
37\end{array}$} & \multirow{2}{*}{$\begin{array}{c}\text { Female } \\
13\end{array}$} & \multirow{2}{*}{$\begin{array}{r}60 y \\
6\end{array}$} & \multirow{2}{*}{$\begin{array}{c}>60 y \\
44\end{array}$} \\
\hline \multirow{5}{*}{ 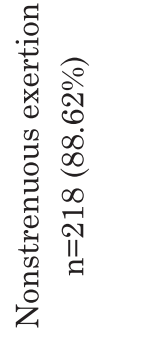 } & MET1 & & & & & \\
\hline & MET 2 & $58(23.6)$ & 42 & 16 & 11 & 47 \\
\hline & MET 3 & $46(18.7)$ & 30 & 16 & 9 & 37 \\
\hline & MET 4 & $33(13.4)$ & 27 & 6 & 4 & 29 \\
\hline & MET 5 & $31(12.6)$ & 21 & 10 & 4 & 27 \\
\hline \multirow{4}{*}{ 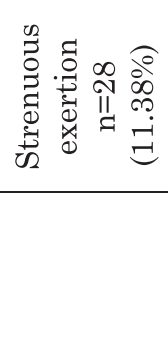 } & MET 6 & $15(6.1)$ & 13 & 2 & 7 & 8 \\
\hline & MET 7 & $6(2.4)$ & 6 & 0 & 2 & 4 \\
\hline & MET 8 & $7(2.8)$ & 7 & 0 & 3 & 4 \\
\hline & $\begin{array}{l}\underset{\pi}{\pi} \\
\stackrel{0}{0} \\
\stackrel{+}{+1}\end{array}$ & 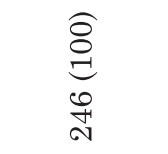 & 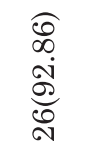 & $\underset{N}{\stackrel{\overbrace{}}{\leftrightarrows}}$ & 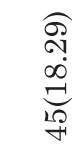 & 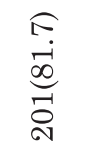 \\
\hline
\end{tabular}

Table-II

Smoking, HTN, DM and Angina status of AMI Patient at different MET Level $(n=246)$.

\begin{tabular}{|c|c|c|c|c|c|c|c|c|c|c|c|}
\hline \multirow{2}{*}{\multicolumn{2}{|c|}{ Level of Exertion }} & \multicolumn{2}{|c|}{ Smoking } & \multicolumn{2}{|c|}{ Diabetes } & \multicolumn{2}{|c|}{ Hypertension } & \multicolumn{2}{|c|}{ Dyslipidaemia } & \multicolumn{2}{|c|}{ Angina } \\
\hline & & \multirow{2}{*}{$\begin{array}{c}\text { Yes } \\
36\end{array}$} & \multirow{2}{*}{$\begin{array}{l}\text { No } \\
14\end{array}$} & \multirow{2}{*}{$\begin{array}{c}\frac{\text { yes }}{32} \\
3\end{array}$} & \multirow{2}{*}{$\frac{\text { no }}{18}$} & \multirow{2}{*}{$\begin{array}{c}\text { yes } \\
43\end{array}$} & \multirow{2}{*}{$\begin{array}{c}\text { No } \\
7\end{array}$} & \multirow{2}{*}{$\begin{array}{c}\text { yes } \\
11\end{array}$} & \multirow{2}{*}{$\begin{array}{l}\text { No } \\
39\end{array}$} & \multirow{2}{*}{$\frac{\text { yes }}{38}$} & \multirow{2}{*}{$\begin{array}{l}\text { No } \\
12\end{array}$} \\
\hline \multirow{5}{*}{ 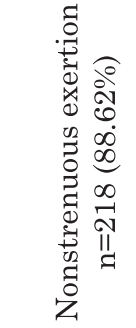 } & MET1 & & & & & & & & & & \\
\hline & MET 2 & 46 & 12 & 40 & 18 & 44 & 14 & 12 & 46 & 36 & 22 \\
\hline & MET 3 & 24 & 22 & 9 & 37 & 35 & 11 & 7 & 39 & 40 & 6 \\
\hline & MET 4 & 18 & 15 & 18 & 15 & 23 & 10 & 8 & 25 & 25 & 8 \\
\hline & MET 5 & 23 & 8 & 11 & 20 & 22 & 9 & 11 & 20 & 31 & 0 \\
\hline \multirow{4}{*}{ 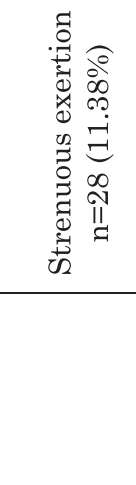 } & MET 6 & 3 & 12 & 2 & 13 & 6 & 9 & 6 & 9 & 7 & 8 \\
\hline & MET 7 & 0 & 6 & 1 & 5 & 1 & 5 & 6 & 0 & 3 & 3 \\
\hline & MET 8 & 0 & 7 & 1 & 6 & 2 & 5 & 7 & 0 & 3 & 4 \\
\hline & 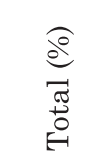 & $\begin{array}{l}\text { के } \\
\stackrel{\circ}{0} \\
\stackrel{0}{0} \\
\stackrel{0}{0} \\
0\end{array}$ & 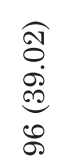 & 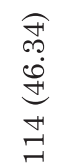 & 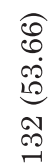 & 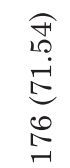 & $\begin{array}{l}\widehat{0} \\
\stackrel{1}{0} \\
0 \\
\stackrel{0}{0} \\
\stackrel{0}{1}\end{array}$ & 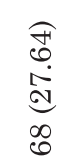 & 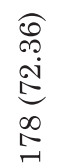 & 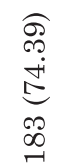 & 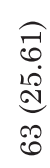 \\
\hline
\end{tabular}


Table-III

Type of activity, Working hour per day and duration for exertion to symptom onset of AMI patient at different MET Level $(n=246)$.

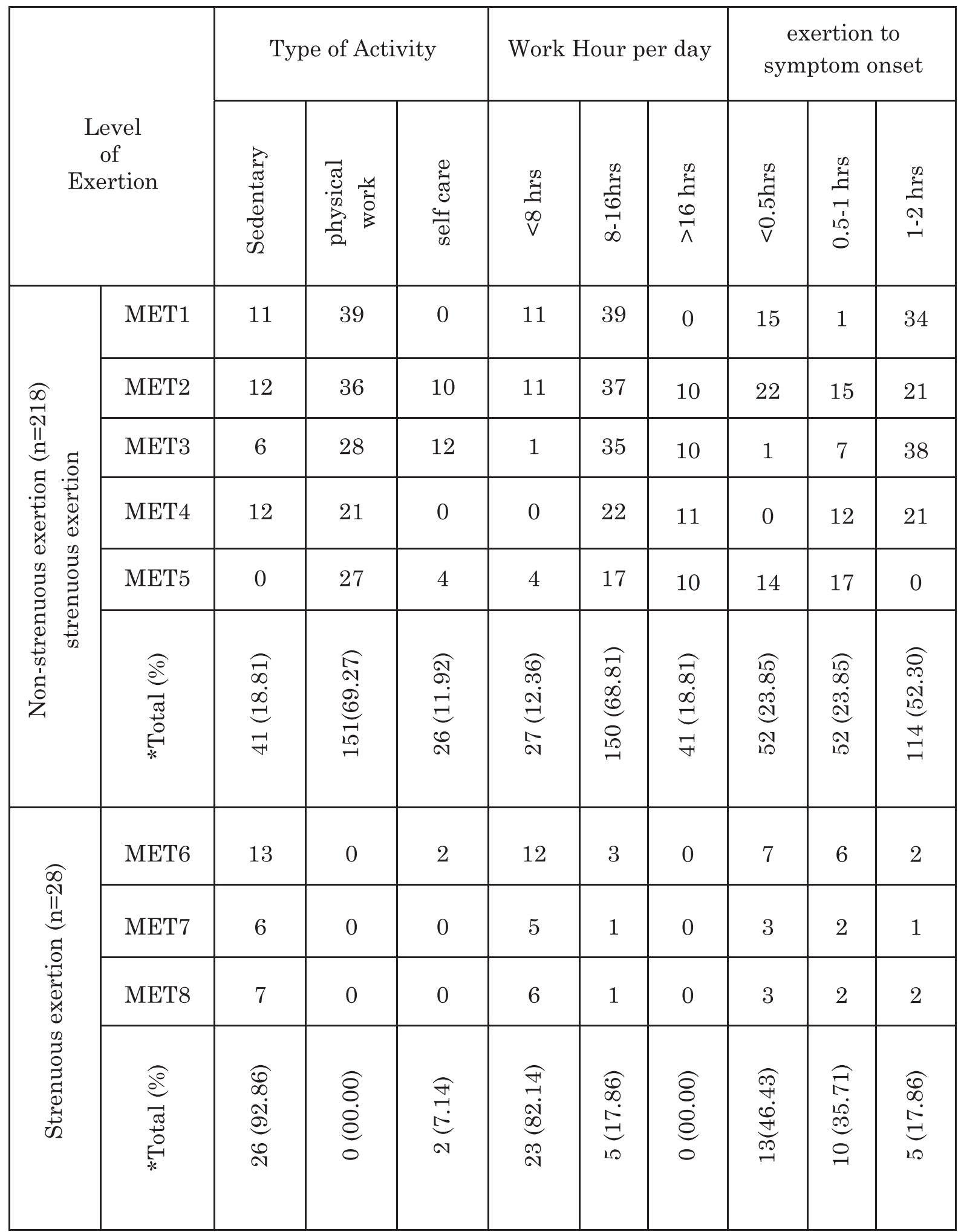


Table-IV

Duration of exertion and Frequency of exertion of AMI patient at different MET Level $(n=246)$.

\begin{tabular}{|c|c|c|c|c|c|c|c|}
\hline \multirow{2}{*}{\multicolumn{2}{|c|}{ Level of Exertion }} & \multicolumn{3}{|c|}{ Duration of exertion } & \multicolumn{3}{|c|}{$\begin{array}{l}\text { Frequency of } \\
\text { exertion }\end{array}$} \\
\hline & & \multirow{2}{*}{ 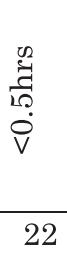 } & \multirow{2}{*}{ 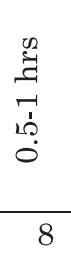 } & \multirow{2}{*}{ 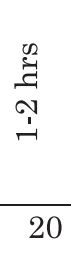 } & \multirow{2}{*}{ 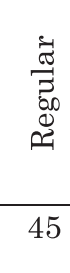 } & \multirow{2}{*}{ 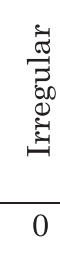 } & \multirow{2}{*}{$\begin{array}{l}\text { శే } \\
\text { ปั } \\
\text { 乙 } \\
\text { A } \\
5\end{array}$} \\
\hline \multirow{6}{*}{ 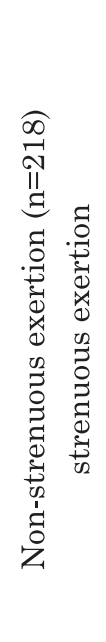 } & MET1 & & & & & & \\
\hline & MET2 & 22 & 18 & 18 & 36 & 12 & 10 \\
\hline & MET3 & 21 & 4 & 21 & 27 & 7 & 12 \\
\hline & MET4 & 14 & 8 & 11 & 21 & 8 & 4 \\
\hline & MET5 & 14 & 7 & 10 & 11 & 09 & 11 \\
\hline & 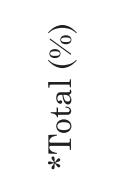 & 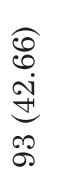 & 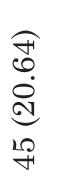 & 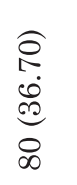 & 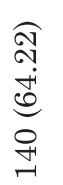 & 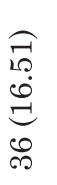 & 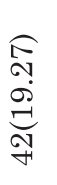 \\
\hline \multirow{4}{*}{ 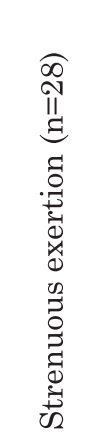 } & MET6 & 0 & 2 & 13 & 6 & 8 & 1 \\
\hline & MET7 & 0 & 1 & 5 & 2 & 4 & 0 \\
\hline & MET8 & 1 & 2 & 4 & 0 & 7 & 0 \\
\hline & 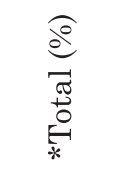 & 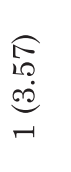 & 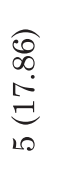 & 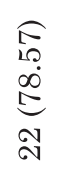 & $\begin{array}{l}\widehat{E} \\
i 0 \\
\infty \\
\stackrel{0}{\mathfrak{d}} \\
\infty\end{array}$ & 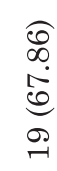 & 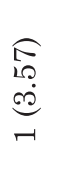 \\
\hline
\end{tabular}

\section{Discussion:}

In this study, strenuous exertion (MET > 6) reported within 2 hour of AMI in 11.38\% of AMI patient. American College of Sports Medicine and the American Heart Association has reported history of vigorous physical activity within 1 hour of AMI in $4 \%$ to $10 \%$ of AMI patients. The difference is not significant in between 1 and 2 hour symptom history prior onset of AMI. The reason is supported by Van Camp that he found $90 \%$ patient showed symptom of AMI within one hour of vigorous exercise. ${ }^{10}$ Like Van Camp several additional studies have found that the onset of myocardial infarction occurred during physical exertion in 5 to 13 percent of cases, which is in the same range of our my findings. ${ }^{11,12}$

The study also showed a relationship between exertion level and acute myocardial infarction which is a negative correlation between AMI and regular physical exertion at different MET level. In a review study Powell found inverse association between regular physical activity and incidence of AMI. ${ }^{13}$ 
Prashand found 64071 patients admitted with an acute myocardial infarction to 49 University Health System Consortium member hospitals in America from 2006 to 2009 and their mean age was 64.9 years. Here, strenuous group are younger. ${ }^{14}$ Besides, the study also showed incidence of AMI over 70 years is more [104(47.70\%) out of 218 ] in non-strenuous group whereas in strenuous group incidence is more [15 (53.57\%) out of 28] in 60-69 age group. ${ }^{14}$

Different studies showed that incidence of AMI are more in male than female. The findings of the study is consistent with that as the study found male are 3 times more than female and it is similar to a study done by PekkaJousilahti. ${ }^{15}$ But male are 1.5 times more in strenuous group than nonstrenuous group in this study.

Stephanie Von Klot et al. found from the Augsburg Coronary Event Registry between February 1999 and December $2003,{ }^{16}$ the risk factor of AMI such HTN, DM, smoking and angina are respectively $72 \%, 26 \%, 22 \%$ and $36 \%$. The study showed incidence of all risks factor are almost twice except HTN which is similar with Stephanie Von Klot study. But interestingly incidence of all risk factors is much less in strenuous group except dyslipidemia rather which is 3 times more in strenuous group.

Strenuous exertion group of AMI patients are all most all sedentary worker. $26(92.86 \%)$ of 28 subjects were sedentary worker. And $151(69.2 \%)$ of 218 patients were physical worker in their profession in non-strenuous group of AMI patients. $68.81 \%$ (150 out of 218 ) patients were working 8-16 hours per day in AMI patient of nonstrenuous group. But in strenuous group maximum patients $(82.14 \%)$ had history of less than 8 hours work per day. A study by Johan Hallqvist, showed non manual worker (low. Middle, high grade) had incidence of AMI after vigorous exertion was far more (59\%) than manual worker (19\%) and self employed (10\%).

Within 2 hours history prior onset of AMI, the study found that number of non- strenuous exertion experienced patient before (47.70\%) and after $(52.30 \%) 1$ hour is same. ${ }^{18}$ So, no conclusive decision can be taken between physical exertion and AMI of such group. In strenuous group, the number of AMI patient is 5 times more $(82.14 \%)$ before 1 hour than after 1 hour (17.86\%) prior symptom onset of AMI. ${ }^{18}$ It may be due to heavy exertion causes AMI within an hour of exertion.

Strenuous exertion group had history longer time exertion (72.57\%, 1-2 hours) than non-strenuous group ( $42.66 \%,<0.5$ hours). Moreover, $67.86 \%$ AMI patient of strenuous exertion group had engaged in irregular exertion whereas most of the patients (64.22\%) of non strenuous group had a history of regular exertion. Irregular and long duration exertion may provoke AMI in heavy exertion group. ${ }^{19}$

\section{Limitations:}

Some patients could not remember exactly what he or she had done within last 2 hour of AMI onset. Few patients could not complete history due to reattack of angina. With the help of attendants, the history of that patients were completed. Another limitation of the study is nonprobability sampling technique. Every patient had not equal chance to be selected. Large sample size would have minimized the bias.

\section{Conclusion:}

The result of the study indicates that a period of strenuous physical activity is associated with increased risk of having acute myocardial infarction, particularly among patients of sedentary worker who have dyslipidemia and who exercise irregularly. Those who exercise regularly have lower chance of AMI as shown by the negative correlation. Most of the AMI occur within two hour of heavy exertion. Hypertension, DM, smoking, ageing and other risk factors are more responsible for AMI who have non-strenuous exertion history.

\section{Recommendations:}

Findings of the study could provide a promising therapeutic strategy for prevention of AMI as well as patient could be counseled about the pattern of exercise to prevent AMI. A prospective study is requiring clarifying accurately an association between level of physical exertion and acute myocardial infarction.

Conflict of Interest - None. 


\section{References:}

1. Smith SC Jr., Blair SN., Bonow RO., Brass LM., Cerqueira MD., DracupK,,et al..AHA/ ACC Guidelines for Preventing Heart Attack and Death in Patients With Atherosclerotic Cardiovascular Disease: 2001 update. A statement for healthcare professionals from the American Heart Association and the American College of Cardiology. J Am Coll Cardiology 2001;38:1581-1583.

2. ToflerGH., Muller JE. Triggering of acute cardiovascular disease and potential preventive strategies. Circulation 2006;114:1863-1872.

3. Wilson PW, D'Agostino RB, Levy' D, Belanger AM, Silbershatz H, Kannel WB. Prediction of coronary heart disease using risk factor categories. Circulation 1998; 18: 1837-1847.

4. Sumiyoshi T, Haze K, Saito M, Fukami K, Goto Y, Hiramori K. Evaluation of clinical factors involved in onset of myocardial infarction. Jpn Circ J 1986; 50: 164-173.

5. Fletcher GF, Blair SN, Blumenthal J. Statement on exercise: benefits and recommendations for physical activity programs for all Americans: a statement for health professionals by the Committee on Exercise and Cardiac Rehabilitation of the Council on Clinical Cardiology, American Heart Association. Circulation 1992; 86: 340-344.

6. Murry A, Malcolm M, Geoffrey H, Tofler JB. Triggering of Myocardial infarction by Heavy Physical Exercis. $N$ Eng J Med 1993: 329:1677-1683.

7. Sallis JF, Haskell WL, Wood PD. Physical activity assessment methodology in the Five-City Project. Am J Epidemiol 1985 Jan;121(1):91-106.

8. Astrand PO, Rodahl K. Textbook of work physiology: physiological bases of exercise. 3rd ed. New York: McGraw-Hill. 1986.

9. Paul D, Barry A, Gary J, Steven N, Mark Estes III, William L, et al.. Exercise and Acute cardiovascular
Events: Placing the Risks into Perspective. Joint statement of American College of Sports Medicine and AHA, special communication;2007: 889-891.

10. Van C, Bloor CM., Mueller FO, Cantu RC and Olson H. Nontraumatic sports death in high school and college athletes. Med Sci Sports Exerc. 1995; 27:41-64.

11. Fitzhugh G, Hamilton BE. Coronary occlusion and fatal angina pectoris: study of the immediate causes and their prevention. JAMA 1933: 100(7): 475-480.

12. Phipps C. Contributory causes of coronary thrombosis. JAMA 1936; 106:761-762.

13. Powell KE, Thompson PD, Caspersen CJ, Kendrick JS. Physical activity and the incidence of coronary heart disease. Annu Rev Public Health 1987; 8: 253-287.

14. Prashant K, Sofia M, Samuel F, Hohmann, Pamela S, Douglas, et al. Ionizing Radiation Exposure to Patients Admitted With Acute Myocardial Infarction in the United States. Circularion 2010; 122(21):2160-2169.

15. Pekka J, Erkki V, Jaakko T, Pekka P. Sex, Age, Cardiovascular Risk Factors, and Coronary Heart Disease. Circulation; 199: 1165-1172.

16. von Klot S, Mittleman MA, Dockery DW, Heier M., Meisinger C, Annette P, et al. Intensity of physical exertion and triggering of myocardial infarction: a casecrossover study. Eur Heart J 2008; 29: 1881-1888.

17. Hallqvist J, Moller J, Ahlbom A, Diderichsen F, Reuterwall C, de Faire U.Does heavy physical exertion trigger myocardial infarction? A case-crossover analysis nested in a population-based case-referent study. Am J Epidemiol 2000; 151: 459-467.

18. Dohi T, DaidaH. Change of concept and pathophysiology in acute coronary syndrome (in Japanese). Nippon Rinsho 2010; 68 (4): 592-596.

19. Maclure M. The case-crossover design: a method for studying transient effects on the risk of acute events. Am J Epidemiol 1991;133:144-153. 